\title{
Lise Öğrencilerinin Riskli Davranışlar Gösterme Düzeyleri İle Okula Bağlanma Düzeyleri Arasındaki İlişkinin İncelenmesi
}

\author{
Hüseyin Şimşek \\ Kırşehir Ahi Evran Üniversitesi, Eğitim Fakültesi, Kırşehir \\ husimsek@hotmail.com \\ ORCID ID: https://orcid.org/0000-0001-7455-3706 \\ Firat Çöplü \\ Kırşehir Ahi Evran Üniversitesi, Sosyal Bilimler Enstitüsü, Kırşehir \\ firat.coplu@outlook.com \\ ORCID ID: https://orcid.org/0000-0001-8173-4564
}

\begin{tabular}{|c|c|c|c|}
\hline \multicolumn{4}{|c|}{ Araştırma Makalesi } \\
\hline Geliş Tarihi: $\quad 27.11 .2017$ & Revize Tarihi: & Kabul Tarihi: & 06.06 .2018 \\
\hline
\end{tabular}

\section{Atıf Bilgisi}

Şimşek, H. ve Çöplü, F. (2018). Lise öğrencilerinin riskli davranışlar gösterme düzeyleri ile okula bağlanma düzeyleri arasındaki ilişkinin incelenmesi, Ahi Evran Üniversitesi Sosyal Bilimler Enstitüsü Dergisi, 4(1), 18-30.

Doi: 10.31592/aeusbed.358223

\section{ÖZ}

$\mathrm{Bu}$ araştırma lise öğrencilerinin riskli davranışlar gösterme düzeyleri ile okula bağlanma durumları arasındaki iliş̧inin çeşitli değişkenler açısından incelenmesi amacıyla yapılmıştır. Araştırmada ilişkisel tarama modeli kullanılmıştır. Araştırmanın çalışma grubu uygun örnekleme yöntemi ile seçilmiş 142'si (\%55) kadın, 117'si (\%45) erkek olmak üzere 259 lise öğrencisinden oluşmaktadır. Araştırmanın verileri kişisel bilgi formu, Ergenlerde Okula Bağlanma Ölçeği ve Riskli Davranışlar Ölçeği kullanılarak elde edilmiştir. Verilerin analizi sonucunda erkeklerin riskli davranış gösterme potansiyeli kadınlara kıyasla daha yüksek bulunmuştur. Araştırma bulguları, öğrenim görülen liseden memnuniyet değişkenine göre riskli davranış gösterme düzeylerinin anlamlı biçimde farklılaştığını göstermiştir. Buna göre öğrenim gördüğü liseden memnun olanların riskli davranış gösterme düzeyleri memnun olmayanlardan düşüktür. Sınıf düzeyinin riskli davranış gösterme düzeyini etkilediği; sınıf düzeyi arttıkça riskli davranışlar gösterme düzeyinin yükseldiği görülmektedir. Analizler sonucunda riskli davranışlar ölçeği puan toplamları ile ergenlerde okula bağlanma ölçeği puan toplamları arasında negatif yönlü orta kuvvette anlamlı bir ilişki bulunmuştur. Okula bağlanma arttıkça riskli davranış gösterme düzeylerinin azaldığı bulgusuna ulaşılmıştır.

Anahtar Kelimeler: Lise öğrencileri, okula bağlanma, riskli davranışlar

\section{The Examination of The Relationship Between The Levels of Showing Risky Behaviors and The Levels of Attachment to School of High School Students}

\begin{abstract}
This study was conducted to examine the relationship between the level of risky behaviors of high school students and their attachment to the school in terms of various variables. Relational screening model was used in the research. The study group is composed of 259 high school students selected by appropriate sampling method of which 142 are female $(55 \%)$ and 117 are male (45\%). Data of the research was obtained using a personal information form, Scale of Attachment to School for Adolescents and Scale of Risky Behaviors. As a result of the analysis of the data, it is seen that males have higher levels of risky behavior than females. The findings of the research showed that the levels of risky behaviors significantly differ according to the variable of learner satisfaction from his/her high school. Accordingly, the level of risky behavior of the students who are satisfied with his/her school is lower than the ones who are not satisfied with his/her school. It is observed that the grade of class influences the level of risky behaviors; when the grade of class increases, the level of showing risky behavior increases as well. As a result of the analyses, it was found that as the attachment to school increases, the level of risky behavior decreases.
\end{abstract}

Keywords: High school students, attachment to school, risky behaviors

\section{Giriş}

Birey yaşamında çeşitli gelişimsel dönemler bulunmakta ve dönemlere göre değişen farklı davranışlar ortaya çıkmaktadır. Bu değişimler sosyolojik, psikolojik ve fizyolojik dinamiklerden etkilenmektedir. Gelişim dönemlerinin başarı ile tamamlanması, bireylerin algıladıkları yaşam kalitesi 
üzerinde doğrudan etkilidir. Birey yaşam algıları ise içerisinde bulundukları toplumu etkileyebilmektedir. Ergenlik dönemi gerek gelişim süreci gerekse ortaya çıkardığ 1 sonuçlar bakımından, bireyi etkilediği kadar topluma da yansımaları olan kritik ve önemli bir gelişim dönemidir.

Koç (2004) ergenliği, fizyolojik olarak erişkinliğe ulaşıncaya kadar geçen gelişimsel bir dönem olarak tanımlanmaktadır. Ergenler, bu dönemde fiziksel olarak olgunlaşmakta, artan sosyal ve akademik sorumluluklarıyla birlikte sosyal ve psikolojik anlamda da gelişmektedirler (Gençtanırım ve Ergene, 2014). Ergenlik döneminde bireylerin kişilik yapısında meydana gelen değişikliklerin yanı sıra fizyolojik değişimler de gözlenir. Bu süreçte kimliği kabullenme, aile içi dinamiklere bakışta değişimler, yetişkinlik hayatına yönelik hazırlıklar ve arayışlar gibi farklılaşmalar gözlemlenir (Set, Dağdeviren ve Aktürk, 2006). Bu dönemde bireyin inançları ve değerleri şekillenmekte; annebabanın ergen üzerindeki etkileri azalmakta, buna karşın akran baskısı artmaktadır. Bu önemli gelişimler sonucunda ergenlerde pek çok davranış değişikliği meydana gelir. Bu davranışlar hem ergenlik dönemi hem de daha sonraki gelişim dönemlerinde bireyin yaşamını önemli ölçüde etkilemektedir. Ergenlik dönemi, riskli davranışların en yoğun biçimde görüldüğü dönemdir (Geçtanırım ve Ergene, 2014). Bu durum ergenlerin fizyolojik ve psikolojik sağlıkları açısından olumsuz etkiler oluşturabilmektedir (Uludağlı ve Sayıl, 2009).

Riskli davranışlar, ergenlik döneminde sık karşılaşılan davranışlardır. Alikaşifoğlu (2008) riskli davranışları doğrudan ya da dolaylı olarak gençlerin sağlık ve iyilik hallerini ve yaşamlarını etkileyen ve potansiyel olarak olumsuz sonuçları olabilecek davranışlar olarak tanımlamaktadır. Buna göre madde kullanımı, şiddet ve güvensiz cinsel ilişki ergenlik çağında sıç̧a rastlanan ve halk sağlığı sorunu olarak kabul edilen riskli davranışlardır. Ayrıca son zamanlarda ruh sağlığı sorunları ve obezite de ergen sağlığını tehdit eden alanlar olarak görülmeye başlanmıştır.

Ergenler; doğuştan getirilen ve biyolojik yapıyla ilgili faktörler, toplum içerisinde kabul görmek ve onaylanmak arzusu, kendi değerini ortaya koyma çabası, işlevsel olmayan baş etme mekanizması gibi faktörler nedeni ile riskli davranışlar sergilemeye yatkındırlar (Gençtanırım Kurt, 2010). Bu bağlamda ergenlerin riskli davranışlar sergileme nedenlerinin birden çok kaynağının olabileceği söylenebilir.

Ergenlerde riskli davranışları açıklayan mevcut kavramsal yapı Problem-Davranış Teorisi (PDT)'ne göre; riskli davranışların ortaya çıkması, ergenlerin kendi sosyal çevrelerindeki bireylerle etkileşimleri ile yakından ilişkilidir (Gençtanırım ve Ergene, 2017). Donovan ve Jessor (1985), Jessor (1998), Zamboanga, Carlo ve Raffaelli (2004) tarafindan bu teorinin uyuşturucu kullanımı, anti-sosyal davranışlar ve riskli cinsel davranışlar gibi riskli davranışları açıkladığı gibi, aynı zamanda ön ergenlik dönemindeki çocuklar ve ergenlere uygulanabileceğini savunulmaktadır. PDT'de ergenlerde riskli davranışlar, tek bir değişkenle açıklanmamaktadır. Bu teori birbirinden farklı ancak birbiriyle ilişkili sosyal unsurlardan oluşan içiçe geçmiş üç sistemden oluşmaktadır. Bunlar kişilik sistemi, algılanan çevre sistemi ve davranış sistemidir. Ergenlerde riskli davranışlar bu sistemlerin etkileşimlerine bağlı olarak açıklanmaktadır (Gençtanırım ve Ergene, 2017).

Ergenlik dönemi aynı zamanda okul dönemini ifade eder. Zira ergen bireyler bu gelişim dönemlerinde zamanlarının çoğunu okulda geçirmektedirler. Bu yüzden ergenlik döneminde gelişim okul süreçleriyle yakından ilişkilidir. Okul, öğrenciler için sadece akademik bilginin kaynağ değil aynı zamanda sosyal davranışların prova edildiği, bireylerin toplumsal davranışlara hazırlandığı bir yapıdır. Okul yaşantıları öğrencilerin sosyal davranışları üzerinde doğrudan etkilidir. Olumlu okul yaşantılarının öğrencilerin zihin ve ruh sağlıkları üzerinde etkili olabileceği düşünülmektedir. Bireylerin ergenlik döneminde okulda edindikleri sosyal ve psikolojik yaşantılar, yetişkinlik yıllarını doğrudan etkileyebilecek bir potansiyele sahiptir. Bu nedenle öğrenim gördükleri okula karşı olumlu tutuma sahip öğrencilerin olumsuz tutum geliştiren öğrencilere kıyasla bilişsel ve duyuşsal olarak olumlu bir gelişim çizgisi göstereceği düşünülmektedir.

Okula bağlanma, okulun bir üyesi olarak değerli olduğuna ve saygı duyulduğuna inanma, gruba ait olma gibi temel psikolojik bir ihtiyaç olarak tanımlanmaktadır (Savi, 2011). Özdemir ve Koruklu 
(2013) okula bağlanmanın çeşitli ortamlarda güvenli ve destekleyici ilişki ağları oluşturma gereksinimi ile ilişkili olduğunu belirtmişlerdir. Duy ve Yıldız (2014)' da bağlanmanın, sosyal ve duygusal iyi oluşun temeli olduğunu; ebeveyne, okula ve öğretmenlere bağlanmanın doğrudan okul başarısını etkilediğini ifade etmektedir.

Okula bağlanmanın öğrencilerin çeşitli davranışları üzerinde etkisi olduğuna ilişkin çalışmalar bulunmaktadır. Karaşar ve Kapçı (2011) tarafından lise öğrencileri üzerinde gerçekleştirilen bir araştırmada, öğretmene bağlanmanın olumlu sosyal davranışı, düşük hiperaktivite belirtilerini ve düşük davranış sorunlarını, okula bağlanma ise düşük duygusal sorunları yordadığı rapor edilmiştir. Yaldız ve Kutlu (2015) tarafından yapılan bir başka araştırmada ise depresif belirtilerin okula bağlanma üzerinde anlamlı düzeyde bir yordayıcıllğa sahip olduğu belirtilmiştir. Bond ve arkadaşları (2007) tarafından 8 yaşındaki çocuklar ile gerçekleştirilen araştırmada, düşük okul bağlılığı gösterip sosyal yanı güçlü olanların ilerleyen yıllarda riskli davranış gösterme eğilimlerinin yüksek olduğu, her ikisi birden düşük olanların ise okulu tamamlama olasılığının az olduğu bulgularına ulaşmışlardır.

$\mathrm{Bu}$ açıklamalar 1şığında ergenlik döneminde okul bağlılığının nasıl geliştiği, okula bağl11ık ile riskli davranışlar arasında nasıl bir ilişki bulunduğu önemli hale gelmektedir. Alan yazında sınırlı çalışmanın olduğu göz önünde bulundurulduğunda böyle bir araştırmanın gerçekleştirilmesinin yararlı olacağı düşünülmüştür. Bu nedenle araştırmanın amacı lise öğrencilerinin riskli davranışlar gösterme düzeyleri ile okula bağlanma düzeyleri arasındaki ilişkinin incelenmesi belirlenmesidir.

\section{Yöntem}

\section{Araștırmanın Modeli}

Araştırmada tarama modellerinden ilişkisel tarama modeli kullanılmıştır. İlişkisel araştırmalar, iki ya da ikiden fazla değişken arasındaki ilişkinin, aynı değişkenleri etkilemeden, değiştirmeden araştırıldığı çalışmalardır (Karasar, 2000).

\section{Araștırmanın Örneklemi}

Araştırmanın çalışma evrenini Niğde ilinde devlet okullarında öğrenim gören lise öğrencileri oluşturmaktadır. Çalışma grubu ise uygun örnekleme yöntemi ile seçilmiştir. Ulaşılabilirlik ve elverişlilik esasına dayalı olan uygun örnekleme yöntemi, bazı araştırma konularında bilgilerin hızlıca toplanması amaciyla tercih edilen bir yöntemdir (Aypay, 2010). Bu yöntemle belirlenen çalışma grubunda toplam 259 lise ögrencisi bulunmaktadır. Yaklaşık \%55'ini kadın, \%45'ini ise erkek öğrencilerin oluşturduğu çalışma grubundaki öğrencilerin; 86's1 birinci sınıf, 116's1 ikinci sınıf ve 57'si üçüncü sinıfta öğrenim görmektedir.

Tablo 1

Araştırmanin Örneklemine İlişkin Demografi Tablosu

\begin{tabular}{|c|c|c|c|c|c|c|c|}
\hline \multicolumn{8}{|c|}{ Sinıf Düzeyi } \\
\hline & & \multicolumn{2}{|c|}{ Birinci Sinıf } & \multicolumn{2}{|c|}{ İkinci Sınıf } & \multicolumn{2}{|c|}{ Üçüncü Sınıf } \\
\hline & & $\mathrm{n}$ & $\%$ & $\mathrm{n}$ & $\%$ & $\mathrm{n}$ & $\%$ \\
\hline \multirow{2}{*}{ Cinsiyet } & Kadın & 50 & 35,2 & 64 & 45,1 & 28 & 19,7 \\
\hline & Erkek & 36 & 30,8 & 52 & 44,4 & 29 & 24,8 \\
\hline
\end{tabular}

\section{Veri Toplama Araçları}

Araştırmada verilerin toplanmasında araştırmacı tarafından geliştirilen kişisel bilgi formu, Ergenlerde Okula Bağlanma Ölçeği, Ebeveyn ve Akranlara Bağlanma Envanteri Kısa Formu kullanılmıştır.

\section{Ergenlerde Okula Bağlanma Ölçeği}


Çocuk ve Ergenlerde Okula Bağlanma Ölçeği (Lise Formu): Hill (2005) tarafindan çocuk ve ergenlerin okula bağlanma düzeylerini değerlendirmek amacıyla geliştirilen "School Attachment Scale", 15 madde ile üç faktörden (öğretmen, arkadaş ve okula bağlanma) oluşmaktadır. Ölçek Savi (2011) tarafindan Türk kültürüne uyarlanmıştır. Elde edilen uyum indeksi değerlerine göre üç boyutlu modelin yeterli uyum verdiği söylenebilir. Yapılan güvenirlik analizinde ise ölçeğin Cronbach Alpha iç tutarlık katsayısı .91, iki yarı test güvenirliğinin ise birinci yarı için .80, ikinci yarı için .74 olduğu görülmüştür (Savi Çakar ve Karataş, 2017).

\section{Riskli Davranışlar Ölçeği}

Gençtanırım ve Ergene (2014) tarafından geliştirilmiştir. Riskli davranışlar antisosyal davranışlar, alkol kullanımı, sigara kullanımı, intihar eğilimi, beslenme alışkanlıkları ve okul terki olmak üzere altı boyutta tanımlanmıştır. Ölçeğin geliştirilmesinde Problem Davranış Kuramı temel alınmıştır. Belirlenen boyutları ölçmek üzere hazırlanan likert tipi ölçek için yapı geçerliği çalışmaları ile iç tutarlık ve test tekrar test güvenirlik katsayıları hesaplanmıştır. Çalışma 2009-2010 eğitim ve öğretim yılında Ankara ve İstanbul İllerinde öğrenimlerine devam eden ortaöğretim öğrencilerinden üç grupla yapılmıştır. Veriler üzerinde yapılan geçerlik ve güvenirlik çalışmaları sonucunda, 1-5 arasında puanlanan, altı boyutta 36 maddenin yer aldığı Riskli Davranışlar Ölçeği geliştirilmiştir. Ölçeğin geçerlik çalışmalarında uzman kanısı, açıklayıcı faktör analizi ve benzeme ölçüt geçerliği yöntemleri kullanılmıştır. Ölçeğin güvenirliği için hesaplanan iç tutarlılık katsayısı.70- .91 arasında değişmektedir. Üç hafta ara ile yapılan ölçümler sonucunda ölçeğin test tekrar test güvenirlik katsayısı ise $.56-.90$ arasında olduğu bulunmuştur.

\section{Verilerin Analizi}

Veriler SPSS paket programına işlenmiş ve çalışmada kullanılacak testleri belirlemek için normallik testi gerçekleştirilmiştir. Çalışma grubu 50 kişiden büyük olan gruplar için Shapiro-Wilk normallik testi kullanılması gerekmektedir. Yapılan Shapiro-Wilk normallik testi sonuçlarına göre verilerin normal dağılım göstermediği görülmüş bu nedenle non-parametrik testler kullanılmıştır. $\mathrm{Bu}$ kapsamda iki kategorili değişkenler için Mann Whitney U test, üç ve daha fazla kategorileri bulunan değişkenlerin analizinde Kruskal Wallis testi ve değişkenlerin birbirlerine etkisinin analizinde Spearman Korelasyon analizi kullanılmıştır.

\section{Bulgular}

Lise öğrencilerinin cinsiyet değişkenine göre riskli davranışlar gösterme düzeyine ilişkin bulgular Tablo 2'de verilmiştir.

Tablo 2

Cinsiyet Değişkenine Göre Riskli Davranış Düzeyleri

\begin{tabular}{lcccccc}
\hline & Cinsiyet & $\mathrm{n}$ & $\begin{array}{c}\text { Sira } \\
\text { Ortalaması }\end{array}$ & $\mathrm{U}$ & $\mathrm{Z}$ & $\mathrm{p}$ \\
\hline \multirow{2}{*}{ Riskli Davranışlar Ölçeği Puan Toplamları } & Kadın & 142 & 121,57 & 7110,500 & $-1,995$ &, $046^{*}$ \\
& Erkek & 117 & 140,23 & & & \\
Antisosyal Davranışlar Alt Boyutu Puan Toplamları & Kadın & 142 & 121,30 & 7071,000 & $-2,065$ &, $039^{*}$ \\
& Erkek & 117 & 140,56 & & & \\
& Kadın & 142 & 119,59 & 6829,000 & $-3,354$ &, $001^{*}$ \\
& Erkek & 117 & 142,63 & & & \\
Alkol Kullanımı Alt Boyutu Puan Toplamları & Kadın & 142 & 116,39 & 6374,500 & $-3,485$ &, $000^{*}$ \\
& Erkek & 117 & 146,52 & & & \\
Sigara Kullanımı Alt Boyutu Puan Toplamları & Kadın & 142 & 139,19 & 7002,500 & $-2,182$ &, $029^{*}$ \\
İntihar Eğilimi Alt Boyutu Puan Toplamları & Erkek & 117 & 118,85 & & & \\
& Kadın & 142 & 138,52 & 7097,500 & $-2,023$ &, $043^{*}$ \\
Beslenme Alışkanlıkları Alt Boyutu Puan Toplamları & Erkek & 117 & 119,66 & & & \\
Okul Terki Alt Boyutu Puan Toplamları & Kadın & 142 & 118,03 & 6607,000 & $-2,985$ &, $003^{*}$
\end{tabular}


Erkek $117 \quad 144,53$

$* \mathrm{p}<.05$

Tablo 2 incelendiğinde cinsiyet değişkenine göre riskli davranış düzeylerinin genel boyutta istatistiksel olarak anlamlı bir farklılık gösterdiği görülmektedir $(\mathrm{p}<.05)$. Buna göre erkeklerin riskli davranışlar ölçeği puan toplamları sıra ortalamalarının $(\bar{X}=140,23)$ kadınların okula bağlanma ölçeği puan toplamları sira ortalamalarından $(\bar{X}=121,57)$ yüksek olduğu görülmektedir.

Tablo 2'deki bulgular, riskli davranışlar ölçeği alt bileşenleri açısından da anlamlı farklılıklar olduğunu göstermektedir. Cinsiyet değişkenine göre antisosyal davranışlar alt boyutu puan toplamları incelendiğinde istatistiksel olarak anlamlı bir farklılık olduğu görülmektedir $(p<.05)$. Erkeklerin antisosyal davranışlar alt boyutu puan toplamları sıra ortalamalarının $(\bar{X}=140,56)$ kadınların puan toplamları sıra ortalamalarından $(\bar{X}=121,30)$ yüksek olduğu görülmektedir.

Cinsiyet değişkenine göre alkol kullanımı alt boyutu puan toplamları incelendiğinde istatistiksel olarak anlamlı bir farklılık olduğu görülmektedir $(\mathrm{p}<.05)$. Erkeklerin alkol kullanımı alt boyutu puan toplamları sira ortalamalarının $(\bar{X}=142,63)$ kadınların puan toplamları sira ortalamalarından $(\bar{X}=119,59)$ yüksek olduğu görülmektedir.

Cinsiyet değişkenine göre sigara kullanımı alt boyutu puan toplamları incelendiğinde istatistiksel olarak anlamlı bir farklılık olduğu görülmektedir $(\mathrm{p}<.05)$. Erkeklerin sigara kullanımı alt boyutu puan toplamları sira ortalamalarının $(\bar{X}=146,52)$ kadınların puan toplamları sira ortalamalarından $(\bar{X}=116,39)$ yüksek olduğu görülmektedir.

Cinsiyet değişkenine göre intihar eğilimi alt boyutu puan toplamları incelendiğinde istatistiksel olarak anlamlı bir farklılık olduğu görülmektedir $(\mathrm{p}<.05)$. Erkeklerin intihar eğilimi alt boyutu puan toplamları sira ortalamalarının $(\bar{X}=118,85)$ kadınların puan toplamları sira ortalamalarından $(\bar{X}=139,19)$ düşük olduğu görülmektedir.

Cinsiyet değişkenine göre beslenme alışkanlıkları alt boyutu puan toplamları incelendiğinde istatistiksel olarak anlamlı bir farklılık olduğu görülmektedir $(\mathrm{p}<.05)$. Erkeklerin beslenme alışkanlıkları alt boyutu puan toplamları sıra ortalamalarının $(\bar{X}=119,66)$ kadınların puan toplamları sira ortalamalarından $(\bar{X}=138,52)$ düşük olduğu görülmektedir.

Cinsiyet değişkenine göre okul terki alt boyutu puan toplamları incelendiğinde istatistiksel olarak anlamlı bir farklılık olduğu görülmektedir $(\mathrm{p}<.05)$. Erkeklerin okul terki alt boyutu puan toplamları sira ortalamalarının $(\bar{X}=144,53)$ kadınların puan toplamları sira ortalamalarından $(\bar{X}=118,03)$ yüksek olduğu görülmektedir.

Lise öğrencilerinin öğrenim görülen liseden memnuniyet değişkenine göre riskli davranışlar gösterme düzeyine ilişkin bulgular aşağıdaki Tablo 3'de verilmiştir..

Tablo 3

Öğrenim Görülen Liseden Memnuniyet Değişkenine Göre Riskli Davranış Düzeyleri

\begin{tabular}{lccccccc}
\hline \multicolumn{1}{c}{ Öğrenim görülen liseden memnuniyet } & & $\mathbf{n}$ & $\begin{array}{c}\text { Sıra } \\
\text { Ortalaması }\end{array}$ & $\mathbf{U}$ & $\mathbf{Z}$ & $\mathbf{p}$ \\
\hline Riskli Davranışlar Ölçeği Puan Toplamları & Evet & 183 & 115,91 & 4376,000 & $-4,698$ &, $000^{*}$ \\
& Hayır & 76 & 163,92 & & & & \\
& Evet & 183 & 117,58 & 4682,000 & $-4,148$ &, $000^{*}$ \\
Antisosyal Davranışlar Alt Boyutu Puan Toplamları & Hayır & 76 & 159,89 & & & \\
& Evet & 183 & 122,77 & 5630,000 & $-3,284$ &, $001 *$ \\
Alkol Kullanımı Alt Boyutu Puan Toplamları & Hayır & 76 & 147,42 & & & & \\
& Evet & 183 & 121,41 & 5381,500 & $-3,100$ &, $002 *$ \\
Sigara Kullanımı Alt Boyutu Puan Toplamları & Hayır & 76 & 150,69 & & & \\
& Evet & 183 & 122,75 & 5627,500 & $-2,425$ &, $015^{*}$ \\
İntihar Eğilimi Alt Boyutu Puan Toplamları & Hayır & 76 & 147,45 & & &
\end{tabular}




\begin{tabular}{lcccccc} 
Beslenme Alışkanlıkları Alt Boyutu Puan Toplamları & Evet & 183 & 124,82 & 6006,000 & $-1,733$ &, $083 *$ \\
& Hayır & 76 & 142,47 & & & \\
& Evet & 183 & 118,65 & 4877,500 & $-3,985$ &, $000 *$ \\
Okul Terki Alt Boyutu Puan Toplamları & Hayır & 76 & 157,32 & & & \\
\hline
\end{tabular}

$* \mathrm{p}<.05$

Tablo 3 incelendiğinde, öğrenim görülen liseden memnuniyet değişkenine göre riskli davranış düzeylerinin genel boyutta istatistiksel olarak anlamlı bir farklılık gösterdiği görülmektedir $(\mathrm{p}<.05)$. Öğrenim görülen liseden memnun olanların riskli davranışlar ölçeği puan toplamları sıra ortalamalarının $(\bar{X}=115,91)$ memnun olmayanların puan toplamları sira ortalamalarından $(\bar{X}=163,92)$ düşük olduğu görülmektedir.

Öğrenim görülen liseden memnuniyet değişkenine göre antisosyal davranışlar alt boyutu puan toplamları incelendiğinde istatistiksel olarak anlamlı bir farklılık olduğu görülmektedir $(p<.05)$. Öğrenim görülen liseden memnun olanların antisosyal davranışlar alt boyutu puan toplamları sıra ortalamalarının $(\bar{X}=117,58)$ memnun olmayanların puan toplamları sira ortalamalarından $(\bar{X}=159,89)$ düşük olduğu görülmektedir.

Öğrenim görülen liseden memnuniyet değişkenine göre alkol kullanımı alt boyutu puan toplamları incelendiğinde istatistiksel olarak anlamlı bir farklılık olduğu görülmektedir $(\mathrm{p}<.05)$. Öğrenim görülen liseden memnun olanların alkol kullanımı alt boyutu puan toplamları sıra ortalamalarının $(\bar{X}=122,77)$ memnun olmayanların puan toplamları sıra ortalamalarından $(\bar{X}=119,59)$ düşük olduğu görülmektedir.

Öğrenim görülen liseden memnuniyet değişkenine göre sigara kullanımı alt boyutu puan toplamları incelendiğinde istatistiksel olarak anlamlı bir farklılık olduğu görülmektedir $(\mathrm{p}<.05)$. Öğrenim görülen liseden memnun olanların sigara kullanımı alt boyutu puan toplamları sıra ortalamalarının $(\bar{X}=121,41)$ memnun olmayanların puan toplamları sira ortalamalarından $(\bar{X}=150,69)$ yüksek olduğu görülmektedir.

Öğrenim görülen liseden memnuniyet değişkenine göre intihar eğilimi alt boyutu puan toplamları incelendiğinde istatistiksel olarak anlamlı bir farklılık olduğu görülmektedir $(\mathrm{p}<.05)$. Öğrenim gördüğg̈ liseden memnun olanların intihar eğilimi alt boyutu puan toplamları sıra ortalamalarının $(\bar{X}=122,75)$ memnun olmayanların puan toplamları sıra ortalamalarından $(\bar{X}=147,45)$ düşük olduğu görülmektedir.

Öğrenim görülen liseden memnuniyet değişkenine göre beslenme alışkanlıkları alt boyutu puan toplamları incelendiğinde istatistiksel olarak anlamlı bir farklılık olduğu görülmektedir ( $\mathrm{p}>.05)$. Öğrenim gördüğü liseden memnun olanların beslenme alışkanlıkları alt boyutu puan toplamları sıra ortalamalarının $(\bar{X}=124,82)$ memnun olmayanların puan toplamları sira ortalamalarından $(\bar{X}=142,47)$ düşük olduğu görülmektedir.

Öğrenim görülen liseden memnuniyet değişkenine göre okul terki alt boyutu puan toplamları incelendiğinde istatistiksel olarak anlamlı bir farklılık olduğu görülmektedir $(\mathrm{p}<.05)$. Memnun olanların okul terki alt boyutu puan toplamları sıra ortalamalarının $(\bar{X}=118,65)$ memnun olmayanların puan toplamları sıra ortalamalarından $(\bar{X}=157,32)$ düşük olduğu görülmektedir.

Lise öğrencilerinin sınıf düzeyi değişkenine göre riskli davranışlar gösterme düzeyine ilişkin bulgular aşağıdaki Tablo 4'de verilmiştir. Tablo 4 incelendiğinde sınıf düzeyi değişkenine göre riskli davranış düzeylerinin genel boyutta istatistiksel olarak anlamlı bir farklılık gösterdiği görülmektedir $(\mathrm{p}<.05)$. Yapılan Tamhane posthoc analizi sonrasinda kategoriler arasında istatistiksel olarak anlamlı bir ilişki görülmemiştir ( $>$ >.05). Sınıf düzeyi değişkenine göre antisosyal davranışlar alt boyutu puan toplamları incelendiğinde istatistiksel olarak anlamlı bir farklılık olmadığı görülmektedir ( $>.05)$. Sınıf düzeyi değişkenine göre alkol kullanımı alt boyutu puan toplamları incelendiğinde istatistiksel olarak anlamlı bir farklılık olmadığ görülmektedir ( $\mathrm{p}>.05)$. 
Sınıf düzeyi değişkenine göre sigara kullanımı alt boyutu puan toplamları incelendiğinde istatistiksel olarak anlamlı bir farklılık olduğu görülmektedir $(\mathrm{p}<.05)$. Yapılan Tamhane posthoc analizi sonuçlarına göre aradaki farklılığın ikinci ve üçüncü sınıflar arasındaki anlamlı ilişkiden kaynaklandığı görülmektedir ( $\mathrm{p}>$.05).

Tablo 4

Sınıf Düzeyi Değişkenine Göre Riskli Davranış Düzeyleri

\begin{tabular}{|c|c|c|c|c|c|}
\hline & Sınıf Düzeyi & $\mathrm{n}$ & $\begin{array}{c}\text { Sira } \\
\text { Ortalamas1 }\end{array}$ & Ki- Kare & $\mathrm{p}$ \\
\hline \multirow{3}{*}{ Riskli Davranışlar Ölçeği Puan Toplamları } & Birinci Sinıf & 86 & 121,24 & 6,126 &, $047^{*}$ \\
\hline & İkinci Sınıf & 116 & 126,01 & & \\
\hline & Üçüncü Sınıf & 57 & 151,32 & & \\
\hline \multirow{3}{*}{ Antisosyal Davranışlar Alt Boyutu Puan Toplamları } & Birinci Sinıf & 86 & 121,24 & 5,004 & ,082 \\
\hline & İkinci Sınıf & 116 & 127,19 & & \\
\hline & Üçüncü Sınıf & 57 & 148,94 & & \\
\hline \multirow{3}{*}{ Alkol Kullanımı Alt Boyutu Puan Toplamları } & Birinci Sınıf & 86 & 132,33 & 3,215 & ,200 \\
\hline & İkinci Sınıf & 116 & 123,78 & & \\
\hline & Üçüncü Sinıf & 57 & 139,15 & & \\
\hline \multirow{3}{*}{ Sigara Kullanımı Alt Boyutu Puan Toplamları } & Birinci Sinıf & 86 & 125,41 & 10,820 &, $004 *$ \\
\hline & İkinci Sınıf & 116 & 120,47 & & \\
\hline & Üçüncü Sınıf & 57 & 156,32 & & \\
\hline \multirow{3}{*}{ İntihar Eğilimi Alt Boyutu Puan Toplamları } & Birinci Sınıf & 86 & 138,03 & 4,532 &, 104 \\
\hline & İkinci Sinıf & 116 & 132,94 & & \\
\hline & Üçüncü Sınıf & 57 & 111,89 & & \\
\hline \multirow{3}{*}{ Beslenme Alışkanlıkları Alt Boyutu Puan Toplamları } & Birinci Sinıf & 86 & 127,24 & 1,882 & ,390 \\
\hline & İkinci Sinıf & 116 & 126,18 & & \\
\hline & Üçüncü Sınıf & 57 & 141,95 & & \\
\hline \multirow{3}{*}{ Okul Terki Alt Boyutu Puan Toplamları } & Birinci Sinıf & 86 & 120,56 & 3,085 & ,214 \\
\hline & İkinci Sınıf & 116 & 131,27 & & \\
\hline & Üçüncü Sınıf & 57 & 141,66 & & \\
\hline
\end{tabular}

$* \mathrm{p}<.05$

Sınıf düzeyi değişkenine göre beslenme alışkanlıkları, intihar eğilimi ve okul terki alt boyutları puan toplamları incelendiğinde istatistiksel olarak anlamlı bir farklılık olmadığı görülmektedir ( $\mathrm{p}>.05)$.

Lise öğrencilerinin okula bağlanma değişkenine göre riskli davranışlar gösterme düzeyine ilişkin bulgular aşağıdaki Tablo 6'de verilmiştir.

Tablo 5

Okula Bağlanma ile Riskli Davranışlar Gösterme Arasındaki İlişki

\begin{tabular}{|c|c|c|c|c|c|c|c|c|c|c|c|c|}
\hline & & 1 & 2 & 3 & 4 & 5 & 6 & 7 & 8 & 9 & 10 & 11 \\
\hline 1) & Ergenlerde Okula Bağlanma & & & & & & & & & & & \\
\hline 2) & Okula Bağlanma Alt Boyutu &, $873^{* *}$ & & & & & & & & & & \\
\hline 3) & $\begin{array}{l}\text { Arkadaşlara Bağlanma Alt } \\
\text { Boyutu }\end{array}$ &, $682^{* *}$ &, $462^{* *}$ & & & & & & & & & \\
\hline 4) & $\begin{array}{l}\text { Öğretmenlere Bağlanma Alt } \\
\text { Boyutu }\end{array}$ &, $804^{* *}$ &, $565^{* *}$ &, $346^{* *}$ & & & & & & & & \\
\hline 5) & Riskli Davranışlar Ölçeği &,$- 421^{* *}$ &,$- 410^{* *}$ &,$- 232^{* *}$ &,$- 369^{* *}$ & & & & & & & \\
\hline 6) & $\begin{array}{l}\text { Antisosyal Davranışlar Alt } \\
\text { Boyutu }\end{array}$ &,$- 290^{* *}$ &,$- 270^{* *}$ &,$- 131^{*}$ &,$- 310^{* *}$ &, $743^{* *}$ & & & & & & \\
\hline 7) & Alkol Kullanımı Alt Boyutu &,$- 174^{* *}$ &,$- 202^{* *}$ &,- 093 &,- 094 &, $522^{* *}$ &, $292^{* *}$ & & & & & \\
\hline 8) & Sigara Kullanımı Alt Boyutu &,$- 174^{* *}$ &,$- 190^{* * *}$ &,- 109 &,$- 135^{*}$ &, $661^{* *}$ &, $421^{* *}$ &, $523^{* *}$ & & & & \\
\hline 9) & İntihar Eğilimi Alt Boyutu &,$- 389^{* *}$ &,$- 349^{* *}$ &,$- 185^{* *}$ &,$- 388^{* *}$ &, $548^{* *}$ &, $325^{* *}$ &, 103 &, $181^{* *}$ & & & \\
\hline
\end{tabular}


10) Beslenme Alışkanlıkları Alt Boyutu

11) Okul Terki Alt Boyutu

\begin{tabular}{|c|c|c|c|c|c|c|c|c|c|}
\hline, $175^{* *}$ &,$- 213^{* *}$ &,- 069 &,$- 133^{*}$ &, $518^{* *}$ &, $331^{* *}$ & ,062 &, $140^{*}$ &, $240^{* * *}$ & \\
\hline 410 &,$- 358^{* *}$ &,$- 294^{* *}$ &,$- 365^{* *}$ &, $671^{* * *}$ &, $447^{* *}$ &, $297^{* *}$ &, $412^{* *}$ &, $285^{* *}$ &, $231^{* * *}$ \\
\hline
\end{tabular}

Tablo 5 incelendiğinde, ergenlerde okula bağlanma ölçeği puan toplamları ile riskli davranışlar ölçeği puan toplamları arasında negatif yönlü orta kuvvette anlamlı bir ilişki $(\mathrm{p}<.05, \mathrm{r}=-$ ,421) olduğu görülmektedir. Yine Tablodaki sonuçlara göre antisosyal davranışlar alt boyutu puan toplamları ile arasında negatif yönlü düşük kuvvette anlamlı bir ilişki $(\mathrm{p}<.05, \mathrm{r}=-, 290)$; alkol kullanımı alt boyutu puan toplamları ile arasında negatif yönlü düşük kuvvette anlamlı bir ilişki ( $\mathrm{p}<.05, \mathrm{r}=-, 174)$; sigara kullanımı alt boyutu puan toplamları ile arasında negatif yönlü düşük kuvvette anlamlı bir ilişki $(\mathrm{p}<.05, \mathrm{r}=-, 174)$; intihar eğilimi alt boyutu puan toplamları ile arasında negatif yönlü orta kuvvette anlamlı bir ilişki $(\mathrm{p}<.05, \mathrm{r}=-, 389)$; beslenme alışkanlıkları alt boyutu puan toplamları ile arasında negatif yönlü düşük kuvvette anlamlı bir ilişki $(\mathrm{p}<.05, \mathrm{r}=-, 175)$; okul terki alt boyutu puan toplamları arasında negatif yönlü orta kuvvette anlamlı bir ilişki $(\mathrm{p}<.05, \mathrm{r}=-, 410)$ bulunmaktadır.

\section{Sonuç, Tartışma ve Öneriler}

Cinsiyet değişkenine göre riskli davranış düzeylerinin genel boyutta istatistiksel olarak anlamlı bir farklılık gösterdiği görülmektedir. Erkeklerin riskli davranışlar ölçeği puan toplamları sıra ortalamalarının kadınların okula bağlanma ölçeği puan toplamları sıra ortalamalarından yüksek olduğu görülmektedir. $\mathrm{Bu}$ araştırmanın sonuçlarına benzer şekilde Karahan ve arkadaşları (2006) çalışmalarında erkek öğrencilerde trafik, madde kullanımı ve toplumsal konumla ilgili risk alma eğiliminin, kız öğrencilere göre daha yüksek düzeyde olduğu saptamışlardır. Erdem, Eke, Ögel ve Taner (2006) araştırmalarında erkeklerde polisle başı belaya giren ve hırsızlık yapan arkadaşı olma riski kızlara göre yaklaşık 2.5 kat, bilerek başkasının malına zarar veren arkadaşı bulunma riski ise 2 kat fazla olduğu bulgusuna ulaşmışlardır. Güler ve arkadaşları da (2009) çalışmalarında erkek öğrencilerde sigara ve alkol kullanım sıklıklarının kadınlarınkinden daha yüksek olduğu bulgusuna ulaşmışlardır.

Öğrenim görülen liseden memnuniyet değişkenine göre riskli davranış düzeylerinin genel boyutta istatistiksel olarak anlamlı bir farklılık gösterdiği görülmektedir. Öğrenim görülen liseden memnun olanların riskli davranışlar ölçeği puan toplamları sıra ortalamalarının memnun olmayanların puan toplamları sira ortalamalarından yüksek olduğu görülmektedir. Diğer bir deyişle öğrenim gördüğü liseden memnun olan öğrencilerin riskli davranış gösterme düzeylerinin daha düşük olduğu bulgusuna ulaşılmıştır. Hallinan (2008) 6, 8 ve 10. Sınıf öğrencileri ve öğretmenleri ile gerçekleştirdiği araştırmasında, okulu seven öğrencilerin daha yüksek akademik başarıya sahip olduğunu ve devamsızlık, okulu asma, okulu bırakma ve disiplin sorunlarına rastlantının okulu sevmeyen öğrencilere göre daha az olduğunu bulgularına ulaşmıştır. Demanet ve Van Houtte (2012) daha yüksek algılanan öğretmen desteği ve okula aitliğin okuldaki kötü davranışların daha az olmasıyla ilgili olduğu bulgusuna ulaşmışlardır. Zhang ve Messner (1996) araştırmalarında okula bağlılık ve okul kalitesinin resmi suçluluğa ilişkin gösterge ile ters orantı gösterdiğini ifade etmişlerdir.

Sınıf düzeyi değişkenine göre riskli davranış düzeylerinin genel boyutta istatistiksel olarak anlamlı bir farklılık gösterdiği görülmektedir. Sınıf düzeyi arttıkça riskli davranışlar gösterme düzeylerinin arttığı görülmüştür. Sever (2015) çalışmasında 11. ve 12. sınıf öğrencilerinin riskli davranışlar gösterme düzeylerinin 9. ve 10. sınıf öğrencilerinin riskli davranışlar gösterme düzeylerinden yüksek olduğu bulgusuna ulaşmıştır. Eneççan ve arkadaşları (2011) tarafindan gerçekleştirilen çalışmada erkek lise öğrencilerinin ve üst sınıflarda öğrenim gören lise öğrencilerinin daha fazla risk altında olduğu sonucuna ulaşmışlardır. Tuncer (2012) çalışmasında ehliyetsiz motorlu araç kullanma ile yüksek sınıf düzeyi değişkeni arasında anlamlı bir ilişki olduğu bulgusuna ulaşmıştır.

Ergenlerde okula bağlanma ölçeği puan toplamları ile riskli davranışlar ölçeği puan toplamları arasında negatif yönlü orta kuvvette anlamlı bir ilişki olduğu görülmektedir. Yani okula bağlanma arttıkça riskli davranışlar gösterme düzeylerinin azaldığı söylenebilir. Bu sonuç ilgili alanyazındaki çalışmalar ile örtüşmektedir. Frey, Ruckhin ve Schwab-Stone (2009) 652 ergen ile yürüttükleri 
araştırmalarında, okula bağlanma düzeylerinin artmasının akademik motivasyonla olduğu kadar şiddet suçluluğu ve agresif inançların daha düşük seviyeleriyle de ilişkilendirilmiştir. Diaz (2005) Minnesota' da bulunan 14 okuldan 159 öğrenci ile gerçekleştirdiği araştırmasında, öğrencilerin okul bağlılığ arttıkça riskli davranışların azaldığı bulgularına ulaştığını ifade etmiştir. Henry ve Slater (2007) yapmış oldukları araştırmada öğrencilerinin okula bağlılığının iyi olduğu okullara katılan öğrencilerin alkol kullanma ihtimalinin daha az olduğu, alkol kullanmaya daha düşük niyetleri olduğu, okuldaki ve çok az arkadaşlarının alkol kullandığını düşündükleri fikrini kuvvetle benimsedikleri ifade edilmiştir.

Erkek öğrencilerin riskli davranışlar gösterme düzeylerinin kadınlara göre daha fazla olduğu; erkeklerin toplumsal cinsiyet rolleri gereği kadınlardan daha korkusuz davranışlar sergileme eğiliminde olması ile bu durumun alakalı olduğu, ayrıca yetişkinlerden sosyal öğrenme yoluyla bazı maddelerin kullanımının özendirici bir unsur olarak çocuk ve ergenlere yansıtıldığı düşünülmektedir. $\mathrm{Bu}$ durumla ilgili olarak sigara kullanımında model faktörüne yönelik çalışmalar üretilebilir. Okullarda ve yakın çevresinde özellikle rol model olarak öğrenciyi doğrudan etkileyen öğretmenlerin sigara tüketimlerine dair düzenlemeler yeniden gözden geçirilebilir. Okul terki eğilimlerinin erkek öğrencilerde yüksek olduğu çalışma sonuçlarında dikkat çekmektedir. Bunun sebeplerinin daha ayrıntılı bir şekilde anlaşılması amacıyla yeni çalışmalar yapılabilir. Liseden memnuniyet değişkeni incelendiğinde öğrenim gördüğü liseden memnun olan ve olmayan öğrencilerin riskli davranış gösterme ve okul bağlılığı düzeylerinde anlamlı farklılıklar olduğu görülmektedir. Öğrencilerin öğrenim gördüğü kurumdan memnuniyetsizlik nedenlerini anlamaya yönelik daha kapsamlı çalışmalar üretilebilir. Öğrencilerin okula bağlllık düzeyleri arttıç̧a riskli davranış gösterme düzeylerinin azaldığ sonucundan hareketle okula bağl1lıkta üç temel faktör olan; okul-arkadaşlar-öğretmen bağl1lıklarına yönelik çalışmalar geliştirilmesinin öğrencilerin riskli davranışlar gösterme sıklıklarına etki edebileceği düşünülmektedir. Okulların bu noktada ilgili ihtiyaç analizlerini yaparak öğrencilerinin kurumdan beklentilerinin neler olduğunu belirleyerek bunları işe koşmaya yönelik faaliyetler gerçekleştirebileceği; arkadaşlara bağlanmada sınıf rehber öğretmenleri ve okul psikolojik danışmanlarının sınıf ve okul içerisindeki çatışmaları gözlemleyerek bu çatışmaların giderilmesine yönelik ilgili programları geliştirebileceği düşünülmektedir. 


\section{Kaynaklar}

Alikaşifoğlu M (2008) Ergenlerde davranışsal sorunlar. İ.Ü Cerrahpaşa Tıp Fakültesi Sürekli Tıp Eğitimi Etkinlikleri, Adolesasan Sağlığı II. Sempozyum Dizisi, İstanbul, s.55.

Aypay, A. (2010). Genel Öz Yeterlik Ölçeği'nin (GÖYÖ) Türkçe'ye uyarlama çalışması. İnönü Üniversitesi Eğitim Fakültesi Dergisi, 11(2),113-131.

Bond, L., Butler, H., Thomas, L., Carlin, J., Glover, S., Bowes, G. ve Patton, G. (2007). Social and school connectedness in early secondary school as predictors of late teenage substance use, mental health, and academic outcomes. Journal of Adolescent Health, 40(4), 357-e9.

Demanet, J. ve Van Houtte, M. (2012). School belonging and school misconduct: The differing role of teacher and peer attachment. Journal of Youth and Adolescence, 41(4), 499-514.

Diaz, J. D. (2005). School attachment among Latino youth in rural Minnesota. Hispanic Journal of Behavioral Sciences, 27(3), 300-318.

Duy, B. ve Yıldız, M. A. (2014). Farklı zorbalık statüsüne sahip erinlerde okula bağlanma ve yalnızlık. Eğitim ve Bilim, 39(174),173-188.

Eneçcan, F. N., Şahin, E. M., Erdal, M., Aktürk, Z. ve Kara, M. (2011). Edirne şehir merkezindeki lise öğrencilerinde riskli sağlık davranışlarının değerlendirilmesi. TAF Preventive Medicine Bulletin, 10(6), 687-700.

Erdem, G., Eke, C. Y., Ögel, K. ve Taner, S. (2006). Lise öğrencilerinde arkadaş özellikleri ve madde kullanımı. Journal of Dependence, 7(3), 111-116.

Frey, A., Ruchkin, V., Martin, A. ve Schwab-Stone, M. (2009). Adolescents in transition: School and family characteristics in the development of violent behaviors entering high school. Child Psychiatry \& Human Development, 40(1), 1-13.

Gençtanırım Kurt, D. (2010). Ergenlerde riskli davranışların yordanması. Yayınlanmamış Doktora Tezi. Hacettepe Üniversitesi Sosyal Bilimler Enstitüsü, Ankara.

Gençtanırım, D. ve Ergene, T. (2014). Riskli davranışları ölçeğinin geliştirilmesi: Geçerlik ve güvenirlik çalışmaları. International Journal of Social Science, 25(1), 125-138.

Gençtanırım, D. ve Ergene, T. (2017). Türk ergenlerde riskli davranışların yordanması Eğitim ve Bilim Cilt 42 (2017) Say1 189 137-152.

Guler, N., Güler, G., Ulusoy, H. ve Bekar, M. (2009). Lise öğrencileri arasında sigara, alkol kullanımı ve intihar düşüncesi sıklığı. Cumhuriyet Medical Journal, 31(4), 340-345.

Hallinan, M. T. (2008). Teacher influences on students' attachment to school. Sociology of Education, 81(3), 271-283.

Henry, K. L. ve Slater, M. D. (2007). The contextual effect of school attachment on young adolescents' alcohol use. Journal of school health, 77(2), 67-74.

Karahan, T. F., Sardoğan, M. E., Gençoğlu, C. ve Yılan, G. (2010). Lise öğrencilerinde trafik, madde kullanımı ve toplumsal konumla ilgili risk alma davranışı. Eğitim ve Bilim, 32(142),72-79.

Karasar, N. (2000). Bilimsel araştırma yöntemi, 10. Baskı, Ankara: Nobel Yayın Dağıtım.

Karaşar, B. ve Kapçı Seyitoğlu, E. G. (2016). Lise öğrencilerinde okula bağlanma ve akademik başarının çeşitli değişkenler açısından incelenmesi. Ankara Üniversitesi Eğitim Bilimleri Fakültesi Dergisi, 49(1), 21-42. 
Koç M (2004). Gelişim psikolojisi açısından ergenlik dönemi ve genel özellikleri. Sosyal Bilimler Enstitüsü Dergisi, 17(2), 231-256.

Özdemir, Y. ve Koruklu, N. (2013). İlk ergenlikte ana-babaya bağlanma, okula bağlanma ve yaşam doyumu. İlköğretim Online, 12(3),836-848.

Savi Çakar, F. ve Karataş, Z. (2017). Ergenlerin okula bağlanmalarının yordayıcıları olarak benlik sayg1s1, okul öfkesi ve yaşam doyumu. Eğitim Ve Bilim, 42(189), 121-136.

Savi, F. (2011). Çocuk ve ergenler için okula bağlanma ölçeği: geçerlik ve güvenirlik çalışması. İlköğretim Online, 10(1), 80-90.

Set, T., Dağdeviren, N. ve Aktürk, Z. (2006). Ergenlerde cinsellik. Genel Tip Dergisi, 16(3), 137-141.

Sever, G. (2015). Lise öğrencilerinin madde kullanma eğilimlerinin algılanan sosyal destek ve riskli davranışlarla ilişkisinin incelenmesi. Yayınlamamış Yüksek Lisans Tezi. Gaziantep Üniversitesi Eğitim Bilimleri Enstitüsü, Gaziantep.

Tuncer, E.N. (2012). Adana'daki lise öğrencilerinde kasıtlı ve kasıtsız yaralanmaya yol açabilecek riskli davranışların yaygınlığı. Yayınlanmamış Tıpta Uzmanlık Tezi. Çukurova Üniversitesi Tıp Fakültesi, Adana.

Uludağlı, N. P. ve Sayıl, M. (2009). Orta ve ileri ergenlik döneminde risk alma davranış1: ebeveyn ve akranların rolü. Türk Psikoloji Yazıları, 12(23), 14-24.

Yıldız, M. A. ve Kutlu, M. (2015). Erinlerde okula bağlanmanın yordayıcısı olarak sosyal kaygı ve depresif belirtilerin incelenmesi. Mustafa Kemal Üniversitesi Sosyal Bilimler Enstitüsü Dergisi, 12(31), 332-345.

Zhang, L. ve Messner, S. F. (1996). School attachment and official delinquency status in the People's Republic of China. In Sociological Forum, 11(2) 285-303. 


\section{Extended Abstract}

\section{Introduction}

Risky behaviors are behaviors that directly or indirectly affect the health and well-being of young people and may have potentially negative consequences that affect their lives (Alikaşifoğlu, 2008). Risky behaviors are also observed during puberty, which is at the same time as school age. Adolescents spend most of their time in school. Thus, adolescent development during which risky behaviors are observed is closely related to school processes.

School attachment is defined as a basic psychological need, such as believing to be respected and be a valuable member of the school in which the student participates, and belonging to a group (Savi, 2011). School attachment is related to the need to create secure and supportive networks in various settings (Özdemir ve Koruklu, 2013). School attachment, which is the basis of good social and emotional well-being, also influences the school success positively.

This study examines how school attachment develops in adolescence, and the relationship between school attachment and risky behaviors. Inadequate literature on that subject suggests that such a study would be useful. For this reason, the study was conducted to examine the relationship between the level of risky behaviors of high school students and the level of their attachment to the school.

\section{Method}

In that study, relational scanning model amond survey models was applied. Relational research is the study examining the relationship between two or more variables (Karasar, 2000). The study's universe constitutes high school students in the public schools in Niğde. The study group was selected by appropriate sampling method. The appropriate sampling method based on accessibility and availability is the preferred method for gathering information quickly in some research subjects (Aypay, 2010). There are a total of 259 high school students in the study group determined via that method. Of the students in the study group, $55 \%$ were women and $45 \%$ were male students; 86 are in the first grade, 116 are in the second grade.

\section{Results and Discussion}

According to the gender variable, it was seen that the risky behavior levels showed a statistically significant difference in the general dimension. According to this, the mean rank of total scores that male students got from the risky behaviors scale are higher than those female students got from the school attachment scale. That result is similar to other related research results. In one study, male students were more likely to take risks regarding traffic, substance use and social status than female students (Karahan et al., 2006). In another research, it was found that the risk of being a friend of a man who entered the rubble by the police and committed a theft was found to be about 2.5 times higher and to be two times more risky to have a friend who consiously damages someone else's property for male students than females (Erdem, Eke, Ogel ve Taner, 2006). Güler et al. (2009) also found that male students had a higher prevalence of smoking and alcohol use than females. The results show that males are more likely to show risky behaviors than females. It is thought that this tendency is related to the fact that males tend to exhibit more fearless behaviors than women due to their gender roles and children and adolescents are motivated to use some materials through social learning from adults is reflected in as an incentive.

The level of risky behaviors in the adolescents showed statistically significant difference according to the variable of high school satisfaction level. Those who are satisfied with the high school they have been studying, got higher scores of mean rank in the risk behaviour scale than those who are not satisfied. Hallinan (2008) who studied with 6th, 8th and 10th grade students and their teachers found that students who like school had higher academic success and that coincidence with disability, school hanging, school dropout and disciplinary problems was less than the students who dislike the school. According to Demanet and Van Houtte (2012), higher perceived teacher support and belonging to school indicate less maltreatment at school. According to another research, school attachment and school quality are inversely related to the indicator of official culpability (Zhang ve Messner, 1996).

According to the class level variable, risky behavior levels of adolescents showed statistically significant difference. Accordingly, as the class level increases, the probability of showing risky behavior increases. In another study, it was reported that levels of risky behaviors of 11th and 12th grade students were higher than those of 9th and 10th grade students showing risky behaviors (Sever, 
2015). In a similar study, male high school students and upper secondary school students were at higher risk (Eneççan et al., 2011). Tuncer (2012) noted that there was a significant relationship between unlicensed driving and high class level variables in his study.

A negative correlation with moderate significiant level was found between the mean of the scores of the school attachment scale and the mean of the scores of the risky behaviors scale in the adolescents. Accordingly, adolescents are less likely to show risky behaviors as their attachment to the school is increased. This result overlaps with some other studies in the field. Frey, Ruckhin, and Schwab-Stone (2009) found that the increase in the school attachment was associated with violent crime and lower levels of aggressive beliefs as well as academic motivation. In a study conducted with adolescents in the United States, it was found that as school attachment increases, risky behaviors decrease (Diaz, 2005). In a similar study, it was stated that the intentions and behaviors to use alcohol of new students participating in schools with high school attachment were decreased (Henry and Slater, 2007).

\section{Recommendations}

Depending on the results obtained, it can be stated that teachers who are role model for adolescents in their schools and immediate environments avoid negative behaviours like smoking and drinking alcohol will decrease risky behaviors in adolescents. It was found for teenage boys who have risky behaviors, school abondenment tendency is high. Further studies can be done about which factors influence the school abondenment tendency, other than risky behaviors. It was seen that dissatisfaction from the school in which they study increases the likelihood of showing school loyalty and risky behavior. New studies on the reasons for school dissatisfaction can be done. As the level of students' attachment to the school increases, the level of risky behaviors decreases. Based on that conclusion, it is thought that conducting studies on school-friends-teacher loyalty, which are three basic factors, can affect the frequency of students' showing risky behaviors. 